\title{
Assessment of the impacts of nonstationarity on watershed runoff using artificial neural networks: a case study in Ardebil, Iran
}

\author{
Kazem Javan ${ }^{1}$ Mohammad Reza Fallah Haghgoo Lialestani ${ }^{2} \cdot$ Hamed Ashouri $^{3}$ • \\ Naser Moosavian ${ }^{2}$
}

Received: 23 June 2015/Accepted: 17 August 2015/Published online: 25 August 2015

(c) Springer International Publishing Switzerland 2015

\begin{abstract}
The purpose of this study is to investigate the impacts of climate change on the runoff of Gharehsoo River Basin in the northwest of Iran. In this research, the outputs of monthly precipitation and temperature data of PRECIS (Providing Regional Climates for Impacts Studies) model, a regional climate model with $50 \times 50 \mathrm{~km}$ spatial resolution on the basis of B2 scenario, is used for the base (1961-1990) and the future (2071-2100) periods. The output results of PRECIS show that the average temperature of the watershed increased up to $2-5^{\circ} \mathrm{C}$, for the period spanning from 2070 to 2100 . In addition, compare to the base period, we are expecting to receive more precipitation in future for the months of January, February, March, September and December. The artificial neural network (ANN) was applied to quantify the future discharge. The results show that in the future, the discharge of Gharehsoo River watershed decreases for all months. Moreover, the peak discharge in the future period happens 1 month earlier, due to increasing in the temperature and earlier start of snow melting season. Finally, 1 and $2{ }^{\circ} \mathrm{C}$ increase in temperature lead to $0.05-8.2 \%$ and $0.1-13.4 \%$ decrease of average monthly discharge, respectively.
\end{abstract}

Keywords Climate change $\cdot$ ANN model $\cdot$ Regional climate model $\cdot$ Gharehsoo River

Kazem Javan

kazem.javan.tmu@gmail.com

1 Department of Civil and Environmental Engineering, Tarbiat Modares University, Tehran, Iran

2 Department of Civil and Environmental Engineering, Ferdowsi University, Mashhad, Iran

3 Departmentof Civil and Environmental Engineering, University of California, Irvine, USA

\author{
Abbreviations \\ ANN Artificial Neural Network \\ FFNN Feed Forward Neural Networks \\ GCMs Global Climate Models \\ IDW Inverse Distance Weighting \\ RCMs Regional Climate Models \\ RBF Radial Basis Functions \\ PRECIS Providing Regional Climates for Impacts \\ Studies \\ SRES Special Report on Emissions Scenarios
}

\section{Introduction}

Climate variability and change can influence the ecosystem, environment and water resources (Arnell 1998). One of the most important impacts of climate change is the changes of regional and local available water (Arnell 1999). Different studies have been performed on the impact of climate variability and change on water resources (e.g., Nash and Gleick 1991; Wilby et al. 1999; Arnell 1998; Yu et al. 2002; Huntington 2003; Ashouri et al. 2008; Javan et al. 2013). The countries like Iran that are located in arid and semiarid regions of the world are continually faced with water resources shortage and scarcity. The Gharehsoo River watershed in this study is one of these basins which plays an important role in the agricultural and economic aspect in Iran.

There are many methods of assessing climate change impacts on water resources. One of these methods is the use of hydrological models and the output of global climate models (GCMs) (Watson et al. 1996). One of the drawbacks of GCMs, however, is their coarse resolution. This issue can be overcome by using Regional Climate Models 
(RCMs). These factors can affect regional hydrological variables such as precipitation. Precipitation data, produced by these models, are more appropriate to be used as input to hydrological models (Gutowski et al. 2003). There are many researches in the world about RCMs usages in hydrological studies (Kay et al. 2006a, b; Fowler and Kilsby 2007; Sujana and Asis 2009). Akhtar et al. (2008) showed that estimate of runoff changes in three river watersheds in the Hindukush-Karakorum-Himalaya region are related to the climate change. In this study, the PRECIS Regional Climate Model was utilized for the simulation of future climate. The results showed that the precipitation and temperature will increase at the end of 21 st century. Vicuna et al. (2011) indicated an analysis of the impacts of climate change on the hydrology of the Limari River watershed, located in Chile with using of a hydrological model and a PRECIS output. The results showed a decreasing in annual mean runoff. Preparation of RCMs output for using as an output in hydrological models is another work which should be done in continuance of these researches. There are many methods for preparing of precipitation and temperature data. In this study, we used Geostatistical methods in the ArcGIS software for spatial downscaling. Changes in downscaled temperature and precipitation series can be used to observed temperature and precipitation series by simple transformation rules. We refer to this method as the delta change method (Hay et al. 2002). In the delta change method, an expected mean temperature change is added to the observed temperature record to obtain a future temperature time series.

Current methods of forecasting runoff fall into four categories: conceptual, metric, physical based and datadriven. Conceptual models incorporate simplified conceptualizations of hydrological processes (Chiew and McMahon 1994). Metric models do not rely on hydrological features or processes but rather are based on unit hydrograph theory (Jakeman et al. 1990). Physical based rainfallrunoff models require considerable data and human effort to calibrate, validate, and test but are extremely useful in understanding the governing physics or processes (VanderKwaak and Loague 2001). Because of the limited resources associated with developing and calibrating conceptual, metric, and physics models (Kokkonen and Jakeman 2001), data-driven hydrological methods have been widely adopted for forecasting runoff. Different studies demonstrated the ability of ANN for runoff simulation (Dawson and Wilby 2001; Han et al. 2007a, b; Bray and Han 2004; Nayak et al. 2005, 2007). Zarghami et al. (2011) used of general circulation models (GCM) to predict the climate change and the three scenarios (A1B, A2 and B1) with the horizons 2020, 2055 and 2090. Their study revealed that the average annual temperature will increase $2.3{ }^{\circ} \mathrm{C}$ and annual precipitation will decrease about $30 \%$ in the middle of this century. Using the artificial neural network (ANN), a model was then built to simulate the impact of climate change on the runoffs in three watersheds. The results showed dramatic reduction in flows.

The major purpose of this paper is to discuss the impact of climate change on surface runoff for Gharehsoo River watershed by analyzing the characteristics of changing temperature and precipitation. The study is based on the data from seven climate stations in watershed, and methods wereused to prepare precipitation and temperature data based on the PRECIS model. Then ANN model is used to simulate the river runoff in the basin.

\section{The study area}

This study was directed for the watershed of Ardebil province in North-western Iran, which lies between latitude $37^{\circ}$ to $38^{\circ} \mathrm{N}$ and longitude $47^{\circ}$ to $48^{\circ} \mathrm{E}$ (Fig. 1). The geographical information and the mean observed climate data for the 7 main synoptic stations of the province for the baseline years between 1951 and 2007 are depicted in Table 1. The mean annual precipitation in this watershed (Table 1) is very little in comparison with world average of $800 \mathrm{~mm}$. In recent years, the water shortage in Ardebil city (the capital of the province) that used in excess of water resource for agricultural province and industry consumptions, become a serious problem for this province. There are very strict conflicts on using its recharge sources as well as new water transfers which are limited. The water providing to the cities is now more vulnerable, and the Ardebil Regional Water Company needs to notice the future trend lines of the climate and their impacts on the water resources. This data help them to understand the extent of uncertainties and the real threats, which they face in future years. The purpose of this research is therefore to predict the climate change and its impact on the water resources for this regional.

\section{Methods}

The algorithm of this study is presented in Fig. 2. It has two important stages: first, it prepares the future meteorological data for the study region under a specific climate change scenario, and second, it evaluates the impacts of climate change on Gharehsoo River watershed by using the ANN approach. Each section is described in details in the followings.

\section{Climate data by PRECIS and preparation}

Despite the increase in the resolution of GCMs, they cannot yet predict meteorological variables for small watersheds. 
Fig. 1 Gharehsoo River watershed and its location in Iran with its topography, drainage network and climate stations



Table 1 The positions and the averages of the precipitation and temperature of seven climate stations

\begin{tabular}{llllllll}
\hline & \multicolumn{2}{l}{ Stations } & & & & \\
\cline { 2 - 7 } & Ardebil & Bile & Foladloo & Jafarloo & Namin & Nir & Koloor Ardebil \\
\hline Latitude $\left({ }^{\circ} \mathrm{E}\right)$ & 38.25 & 38.02 & 38.12 & 37.92 & 38.42 & 38.03 & 38.20 \\
Longitude $\left({ }^{\circ} \mathrm{N}\right)$ & 48.28 & 48.60 & 48.48 & 48.35 & 48.45 & 47.98 & 48.08 \\
Elavation $(\mathrm{m})$ & 1332 & 1680 & 1490 & 1680 & 1500 & 1450 & 1581 \\
Available data (years) & $1951-2007$ & $1975-2007$ & $1994-2007$ & $1969-2007$ & $1960-2007$ & $1960-2007$ & $1975-2007$ \\
Mean precipitation $(\mathrm{mm})$ & 445 & 480 & 334 & 359 & 360 & 376 & 458 \\
Mean temperature $\left({ }^{\circ} \mathrm{C}\right)$ & 10.3 & 8.4 & 6.3 & 7.6 & 8.3 & 7.4 & 8.4 \\
\hline
\end{tabular}

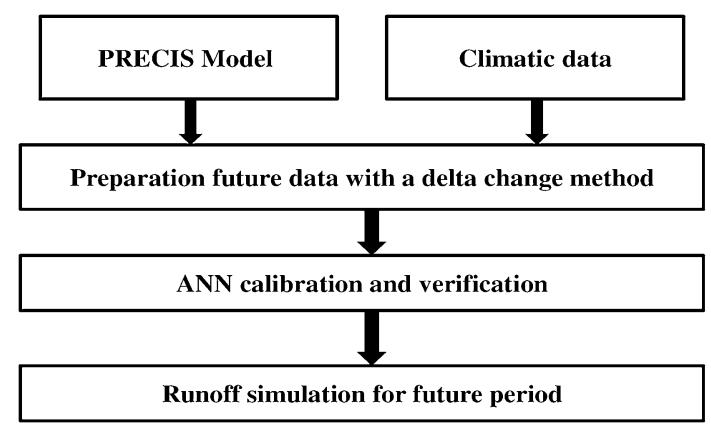

Fig. 2 Algorithm of study

Different dynamic and statistical models have developed to downscale the GCM outputs (Zarghami et al. 2011). The PRECISmodel is a RCMthat it was developed by the Hadley center on the basis of the atmospheric of HadCM3 (Gordon et al. 2000) to generate high resolution climate change scenarios, which was described in Jones et al. 2004. The PRECIS simulated region with a horizontal resolution of $50 \times 50 \mathrm{~km}$. The base climate (1961-1990) and future climate SRES B2 scenario (2071-2100) have been selected. There is enough overlap between the base period and the range of historical observations (1951-2007) to consider that their aggregated statistics should represent the same conditions. Moreover, statistical analysis of the temperature and precipitation series depict that their standard deviation and mean increased for both periods, which are statistically indistinguishable at the $93 \%$ confidence level. For downscaling data we used interpolation methods for preparation precipitation and temperature patterns. Utilizing interpolation methods to estimate hydrological parameters can increase the accuracy of rainfall-runoff calculations (Johnston et al. 2001). These methods include inverse distance weighting (IDW), Global polynomial, Local polynomial, radial basis functions (RBF), Ordinary Kriging and Simple Kriging. The cross validation technique utilized for identification of the best interpolation technique. The delta change method has been applied in many climate change impact studies in the past (see e.g., 
Arnell 1999; Gellens and Roulin 1998; Middelkoop et al. 2001; Akhtar et al. 2008). In this method, the observed meteorological time series were adapted with simulated monthly climate change from PRECIS. The observational database used for delta change method covers the period 1961-1990. The future daily temperature $\left(T_{f, d a i l y}\right)$ and daily precipitation $\left(\mathrm{P}_{\mathrm{f}, \text { daily. }}\right.$ ) time series are generated by Eqs. (1) and (2), respectively.

$$
\begin{aligned}
& T_{\mathrm{f}, \text { daily }}=T_{\mathrm{o} \text {,daily }}+\left(\bar{T}_{\mathrm{f}, \text { monthly }}-\bar{T}_{\mathrm{p}, \text { monthly }}\right) \\
& P_{\mathrm{f}, \text { daily }}=\mathrm{P}_{\mathrm{o} \text {,daily }} \times \frac{\overline{\mathrm{P}}_{\mathrm{f} \text {,monthly }}}{\overline{\mathrm{P}}_{\mathrm{p} \text {,monthly }}}
\end{aligned}
$$

where $T_{\mathrm{o} \text {,daily }}$ is the observed daily temperature, $\mathrm{P}_{\mathrm{o} \text {,daily }}$ is the observed daily precipitation, $\bar{T}_{\mathrm{f} \text {,monthly }}$ is the mean monthly PRECIS simulated future temperature, $\bar{T}_{\mathrm{p} \text {,monthly }}$ is the mean monthly PRECIS simulated present temperature, $\overline{\mathrm{P}}_{\mathrm{f} \text {,monthly }}$ is the mean monthly PRECIS simulated future precipitation and $\overline{\mathrm{P}}_{\mathrm{p} \text {,monthly }}$ is the mean monthly PRECIS simulated present precipitation.

\section{Artificial neural network (ANN)}

The ANN technique has attracted a great deal of attention due to its pattern recognition capabilities. ANNs with one hidden layer are commonly used in hydrologic modeling (Dawson and Wilby 2001; De Vos and Rientjes 2005) since these networks are considered to provide enough complexity to accurately simulate the nonlinear-properties of the hydrologic process.

A FFNN consists of at least three layers, input, output and hidden layers (Hagan and Menhaj 1994; Hagan et al. 1996). The transfer function used in this study is the Sigmoid Function. The sigmoid transfer function allows nonlinearity to be introduced in the neural network processing and is broadly used in ANN modeling (Shamseldin 1997).

The input signals presented to the system in input layer are processed in forward through to the hidden layer. The input signal can be a single signal or an array of signals, whereas the output signal is typically single. The summation of weighted input signals is transferred by a nonlinear activation function. The response of network is compared with the actual observation results and the network error is calculated. The error of network is propagated backwards through the system and the weight coefficients updated (Fig. 3).

The most common ANN network is the feed-forward network, which uses the back-propagation algorithm for calibration (Bougadis et al. 2005). The number of neurons contained in the input and output layers, which are determined by the number of input and output variables of a given system. The size or number of neurons of a hidden layer is an important consideration when solving problems

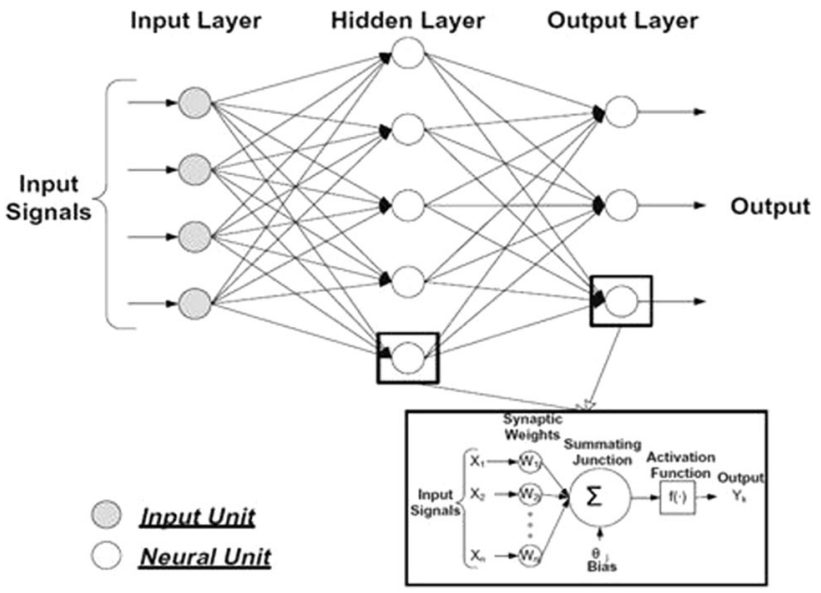

Fig. 3 A three-layered FFNN with a back-propagation calibrating algorithm (Chang et al. 2010)

using multilayer feed-forward networks. If there are fewer neurons within a hidden layer, there may not be enough opportunity for the neural network to capture the intricate relationships between indicator parameters and the computed output parameters. Here, we used three-layer FFNN with one hidden layer and the common trial and error method to select the number of hidden nodes. Too many hidden layer neurons not only require a large computational time for accurate calibrating, but may also result in overtraining. A neural network is said to be "overtrained" when the network focuses on the characteristics of individual data points rather than just capturing the general patterns present in the entire calibrating set.

Understanding the temporal relationship between climatic variables and runoff is fundamental to the model development. To predict one lead day runoff $\mathrm{Q}_{(\mathrm{t}+1)}$, different variants of input variables are considered. The best MLP architecture is chosen according to MSE criterion. Therefore a total number of six variables were identified as inputs (Eq. 3).

$Q_{t}=f\left(P_{t-1}, P_{t-2}, P_{t-3}, P_{t-4}, T_{t-1}, T_{t-2}\right)$

After the appropriate input vector was identified, the network was trained to predict future data based on past and present data. In the present study, the input and output variables are first normalized linearly in the range of 0 and 1 , the normalization is done using the following equation:

$\bar{X}=\frac{X-X_{\min }}{X_{\max }-X_{\min }}$

where $\bar{X}$ is the standardized value of the input, $\mathrm{X}$ is the original data set, $X_{\min }$ and $X_{\max }$ are respectively, the minimum and maximum of the actual values, in all observations. The main reason for standardizing the data matrix is that the variables are usually measured in different units. By standardizing the variables and recasting them in 
dimensionless units, the arbitrary impact of similarity between objects is removed.

Figures 4 and 5 show discharge output of ANN model in calibration and validation periods based on observed data, respectively. A very good match is obtained between the observed runoff values and those computed by the ANN model for the training data in all the input. The training input dataset includes total 2557 data records between 1998 and 2004. The testing input dataset consists of a total 729 data record, observed in the last 2 years (2005-2007). The $\mathrm{R}^{2}$ for the ANN model 0.950 for the calibration period and 0.962 for the validation period.

\section{Results and discussion}

\section{Future changes in precipitation and temperature}

Figure 6 shows the average of 30 years of monthly temperature data in Ardabil station for the base (solid line) and future (dash line) periods. As it is shown, this scenario forecasts that temperature increased in Ardabil station for all seasons. Temperature increases $2-4{ }^{\circ} \mathrm{C}$ in winter, $2-5{ }^{\circ} \mathrm{C}$ in spring, $3-5{ }^{\circ} \mathrm{C}$ in summer and $2-4{ }^{\circ} \mathrm{C}$ in autumn. Maximum temperature will happen in July and the Minimum temperature will take place in January. Figure 7 shows the average of 30-years monthly precipitation in Ardabil station for base and future periods. Future precipitation is more than the base precipitation on January, February, March, September and December.

The PRECIS model forecasts maximum precipitation that happens on February and minimum on July. It is concluded that climate change impacts on climate variables such as precipitation and temperature in Gharehsoo River watershed for future; although according to Figs. 4 and 5, the impact of climate change on temperature would be more than precipitation. Comparison between observed data and the PRECIS model simulated data of the base period (1961-1990) demonstrated that there is an appropriate similarity between these two data sets; so that, the base data sets of the PRECIS model could be used for runoff simulation using ANN during the base period. Statistical analysis of precipitation and temperature data series (observed and output data of the PRECIS model) shows that these two time series had approximately the same mean and standard deviation. In order to prepare base monthly precipitation and temperature patterns, different geostatistical methods are compared to each other using cross validation technique. The sample of precipitation pattern in January of 2100 is shown in Fig. 8.

\section{Future discharge results}

After calibration and validation of ANN model to the watershed, PRECIS model base and future data series used as the input to ANN model. Table 2 shows the difference between monthly discharge for base (1961-1990) and future (2071-2100) periods. Except April, monthly discharges of future period decrease in all of the months. The differences between monthly discharge of base and future periods in summer months are more than the other months; this is because of increase of future temperature and evapotranspiration and decrease of future precipitation in the warm months in comparison with base data. The least discharge difference is $37 \%$, which takes place on April. The same changes for the precipitation and temperature for seven stations are used the PRECIS model and geostatistical methods. The results show that RBF and IDW

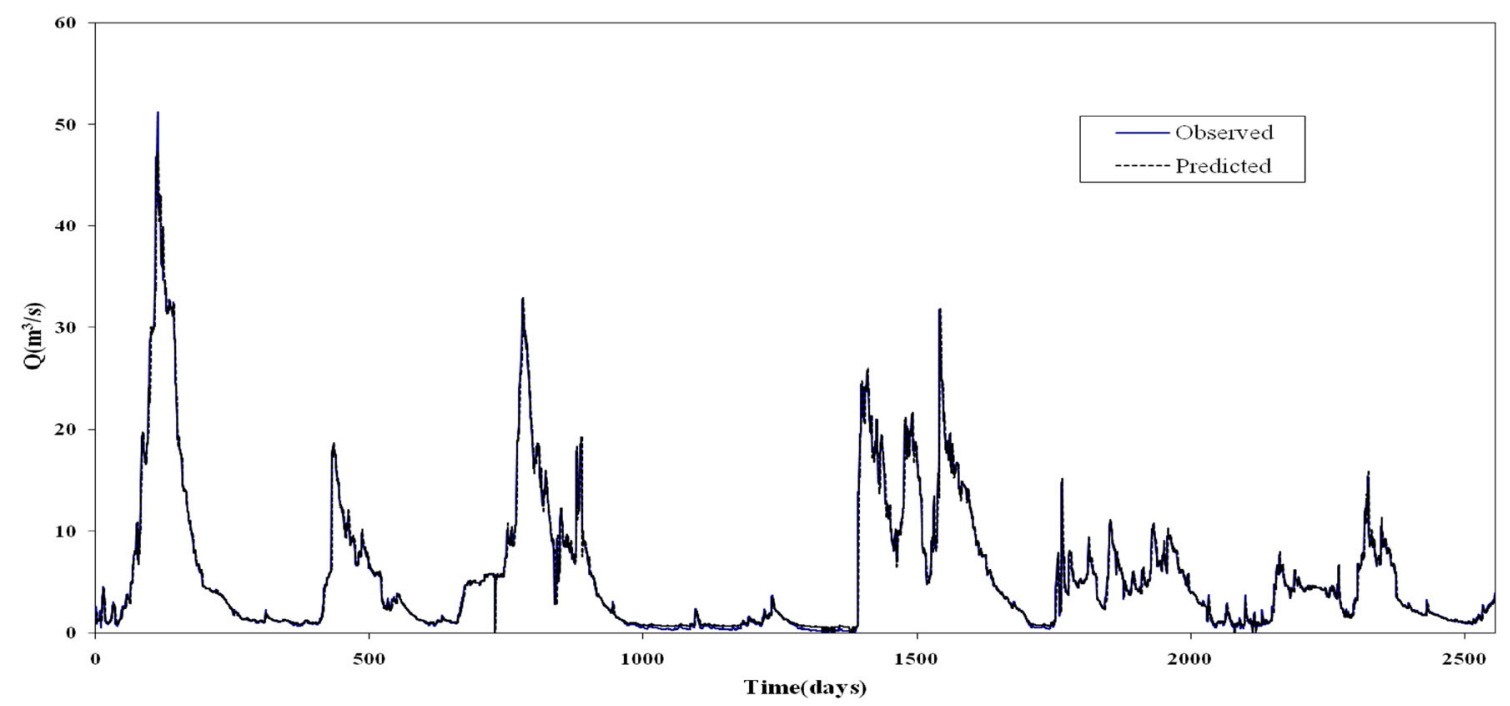

Fig. 4 Analysis plot for daily flow in calibration period with ANN model $\left(\mathrm{m}^{3} / \mathrm{s}\right)$ 


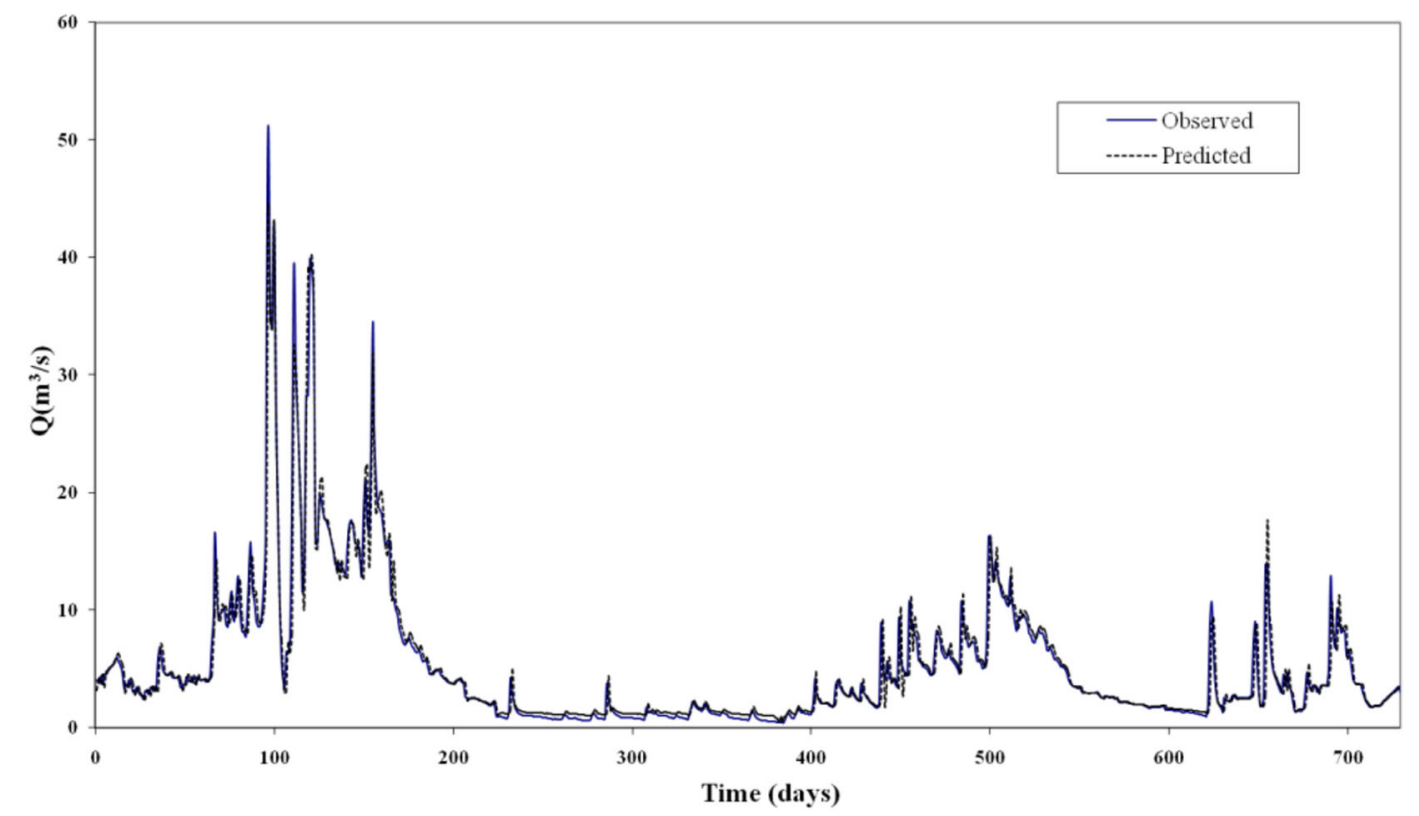

Fig. 5 Analysis plot for daily flow in validation period with ANN model $\left(\mathrm{m}^{3} / \mathrm{s}\right)$

Fig. 6 Mean temperature in Ardabil station for the base (1961-1990) and future (2070-2100) period

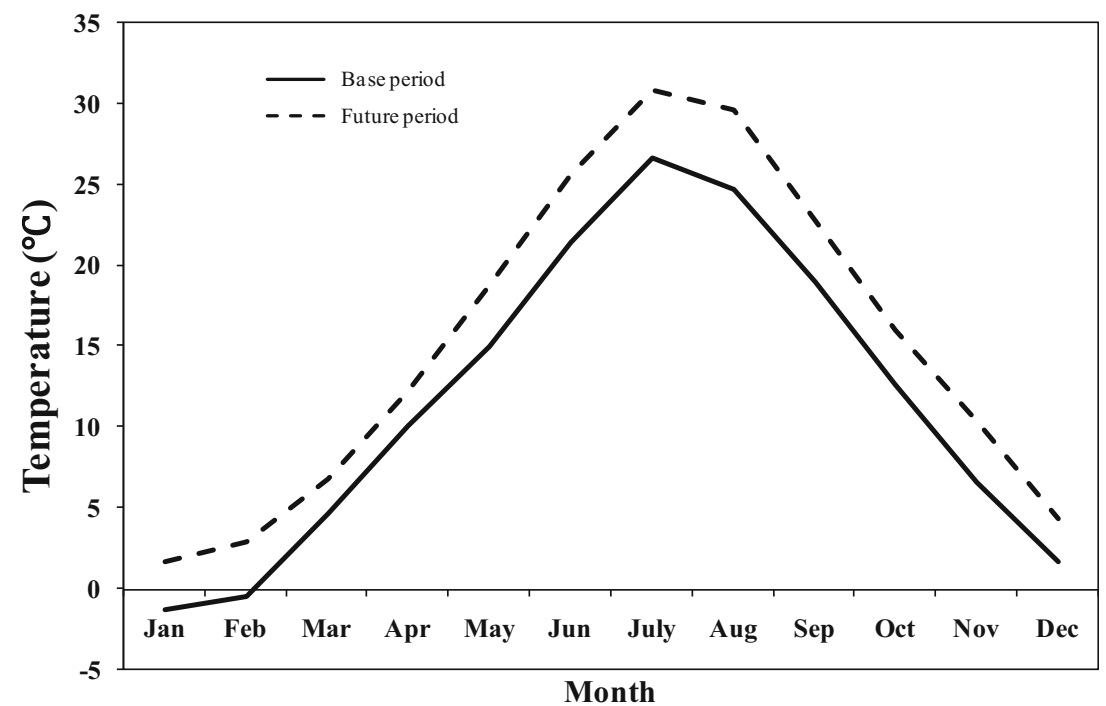

methods can be utilized for preparation of precipitation and temperature patterns.

Figure 9 shows monthly discharge in the future and base periods. Temperature changes mostly affect the timing of runoff. Increasing temperatures lead to earlier runoff in spring, and reduced flows in summer and autumn-at least in the absence of changes in precipitation. Generally, results show that in the future, the discharge of Gharehsoo River watershed would decrease for all months. It might cause problem for agriculture of studied region; because, Gharehsoo watershed is one of the most important regions for production of crops in Iran and plays an important role in economic growth and food.
The data can showed by aridity indexes and These indices are quantitative indicators of the degree of the water deficiency that is present at a given location (Ranjan et al. 2006). A modified aridity index of De Martonne (1926), which requires minimal data, is used here as:

$I=\frac{\mathrm{P}}{\mathrm{T}+10}$

$\mathrm{P}$ : mean annual precipitation $(\mathrm{mm}), \mathrm{T}$ : mean annual temperature $\left({ }^{\circ} \mathrm{C}\right)$ of the site. If the value of I was within the range of 10-19.99, then the climate was classified as semiarid; if it was below 10, then it was classified as an arid region (Neira Mendez 2005). 
Fig. 7 Mean precipitationin Ardabil station for the base (1961-1990) and future (2070-2100) period

Fig. 8 Precipitation pattern on January of 2100
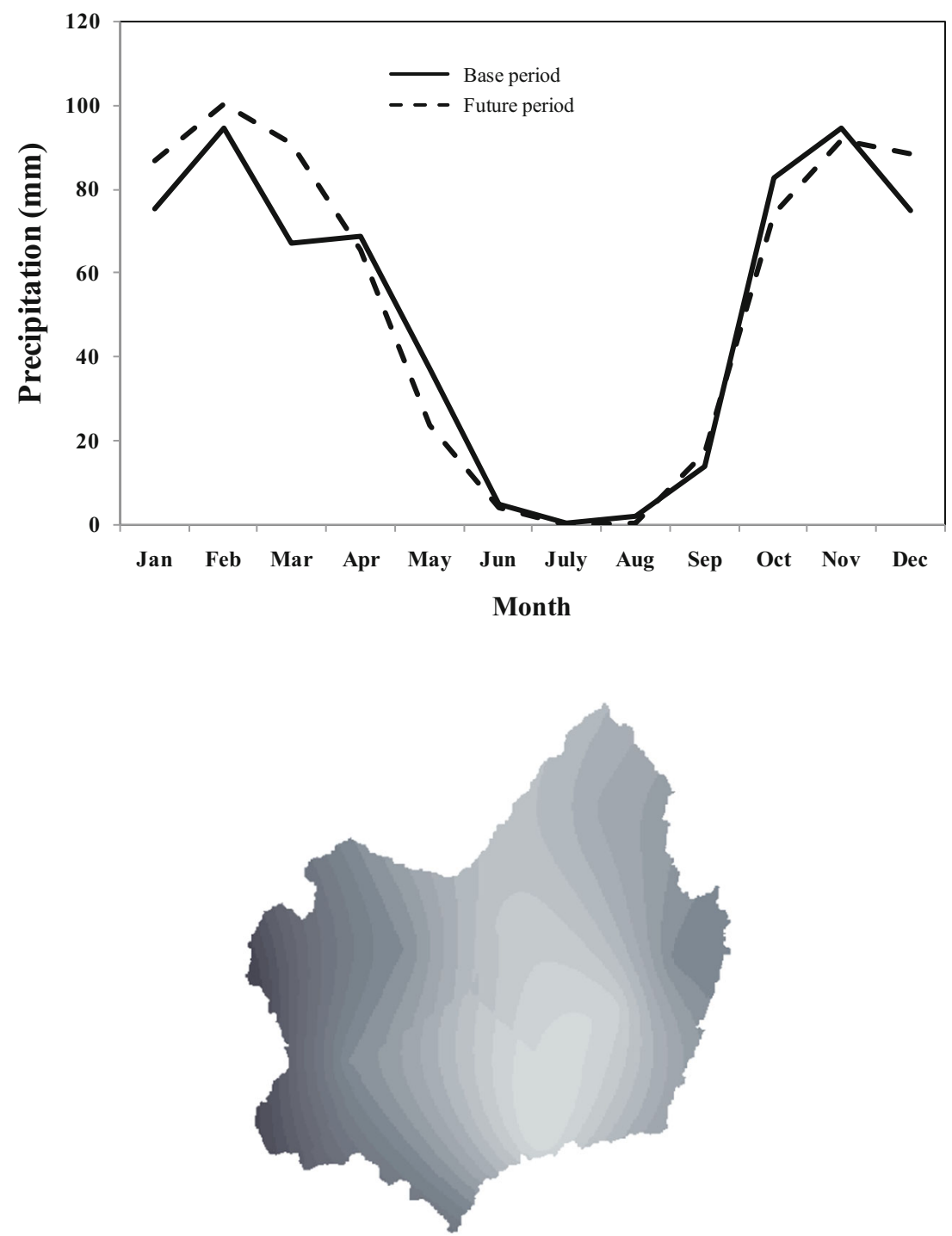

PRECIPITATION (mm)

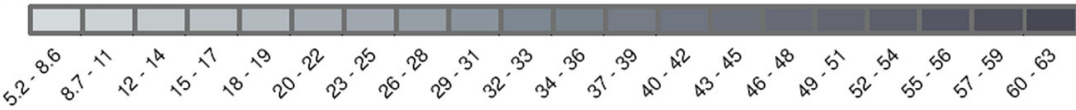

Table 2 The difference between monthly discharges in the base and future periods

\begin{tabular}{lrrrrrrrrrrrrr}
\hline Period & Jan & Feb & Mar & Apr & May & Jun & Jul & Aug & Sep & Oct & Nov & Dec \\
\hline Base period & 22.78 & 11.16 & 19.36 & 53.42 & 82.35 & 77.82 & 37.639 & 16.38 & 8.12 & 6.47 & 32.34 & 78.46 \\
Future period & 20.32 & 8.45 & 13.78 & 55.39 & 58.94 & 50.45 & 22.82 & 9.32 & 1.23 & 3.05 & 12.77 & 52.39 \\
Changes & -2.46 & -2.71 & -5.58 & 1.97 & -23.41 & -27.38 & -14.82 & -7.07 & -6.89 & -3.42 & -19.58 & -26.07 \\
Percent of changes & -10.80 & -24.31 & -28.84 & 3.70 & -28.43 & -35.18 & -39.37 & -43.12 & -84.86 & -52.89 & -60.52 & -33.23 \\
\hline
\end{tabular}

Based on Table 3, the De Martonne aridity index will significantly decrease in the last years of the century, it will be reduced by up to $45 \%$. This result showed that the climate of the province will change from semi-arid to arid at the end of this century that will be worrying for in province future. 
Fig. 9 Monthly discharge future and base period

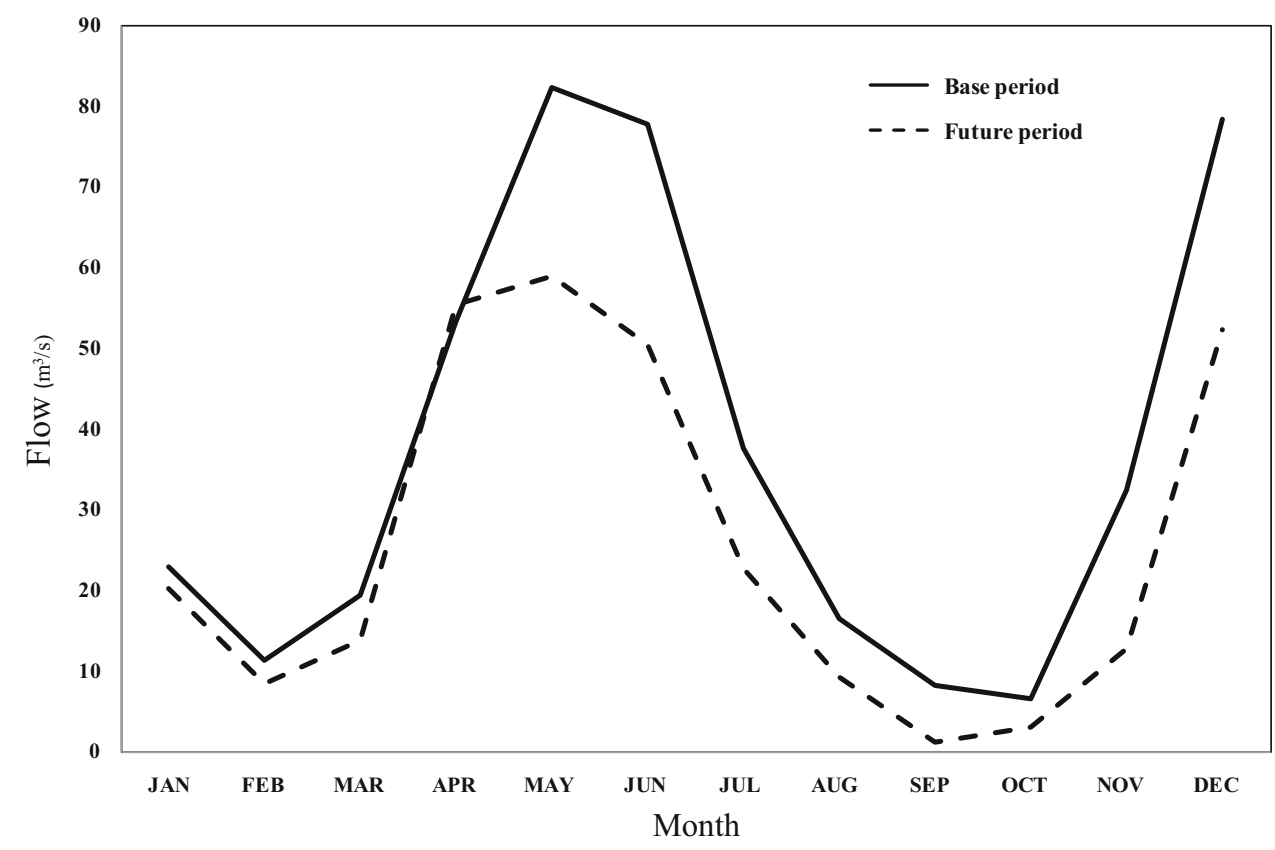

\begin{tabular}{llll}
\hline $\begin{array}{l}\text { Baseline period } \\
(1961-1990)\end{array}$ & 13.45 & & \\
\cline { 2 - 4 } Furture period & $\begin{array}{l}\text { Change in mean annual } \\
\text { precipitation }(\mathrm{mm})\end{array}$ & $\begin{array}{l}\text { Change in mean annual } \\
\text { temperature }\left({ }^{\circ} \mathrm{C}\right)\end{array}$ & $\begin{array}{l}\text { Predicted De } \\
\text { Martonne index }\end{array}$ \\
\hline $2071-2100$ & -52.35 & 3.67 & 8.3 \\
\hline
\end{tabular}

Table 3 The average change in the De Martonne aridity index of the Gharesoo basin under scenario B2
Table 4 Hypothetical scenarios of future climate

\begin{tabular}{lllll}
\hline & & \multicolumn{2}{l}{ Precipitation scenarios } \\
\cline { 3 - 5 } & & $\Delta \mathrm{P}=-20 \%$ & $\Delta \mathrm{P}=+20 \%$ & $\Delta \mathrm{P}=0$ \\
\hline Temperature scenarios & $\Delta \mathrm{T}=0$ & $\square$ & $\square$ & - \\
$\Delta \mathrm{T}=1{ }^{\circ} \mathrm{C}$ & - & - & $\square$ \\
$\Delta \mathrm{T}=2{ }^{\circ} \mathrm{C}$ & - & - & $\square \mathrm{s}$ \\
\hline
\end{tabular}

\section{Sensitivity analysis}

In this section, the sensitivity of precipitation and temperature to runoff is investigated. Sensitivity analysis is performed in four hypothetical scenarios for future climate (Table 4). In two hypothetical scenarios, the precipitation is increased and decreased $20 \%$. In the other scenarios, the temperature is increased 1 and $2{ }^{\circ} \mathrm{C}$. Results of sensitivity analysis are exhibited in Fig. 10. It is obvious that 1 and $2{ }^{\circ} \mathrm{C}$ increase of temperature lead to $0.05-8.2 \%$ and $0.1-13.4 \%$ decrease of average monthly discharge, respectively. In addition, Fig. 10 exhibits that monthly discharge increase $2.3-35.2 \%$ due to $20 \%$ increase of precipitation. Similarly, monthly discharge decreases 1.4-29.4\% due to $20 \%$ decrease of precipitation.

The results of Fig. 8 show that the runoff of Gharehsoo River has a stronger response to the increase of precipitation than to the increase of temperature, specially in spring season. These results are consistent with the fact that the variation of precipitation increase is much greater than the temperature change during spring and the total volume increase in basin flow is largely contributed by the precipitation other than the effect of evaporation and melting of Sabalan mountain snows. However, the impact of temperature and evaporation becomes more ditincted in the dry periods. 
Fig. 10 Results of sensitivity analysis of mean monthly runoff to the precipitation and temperature in the Gharehsoo River watershed



\section{Conclusion}

This study presents a method for modeling the impact of climate change on runoff prediction and demonstrates the advantage of using ANNs model for simulation such nonlinear hydrologic behavior. In this research, different geostatistical methods were utilized for estimation of future patterns of precipitation and temperature. The PRECIS as a regional climate model was utilized to produce climate data of base (1961-1990) and future (2071-2100) periods based on B2 scenario with $50 \times 50 \mathrm{~km}^{2}$ resolution. The capability of RCM'sin simulating the magnitude and spatial variability of current (1961-1990) temperature and precipitation over the Gharehsoo River watershed was investigated. In addition, by combination of base and future precipitation and temperature data with the help of geostatistical methods, the future patterns for monthly precipitation and temperature extracted. The comparison between base and future monthly precipitation and temperature data showed that the future precipitation is more than the base precipitation on January, February, March, September and December. Moreover, future temperature increases $2-4{ }^{\circ} \mathrm{C}$ in winter, $2-5{ }^{\circ} \mathrm{C}$ in spring, $3-5{ }^{\circ} \mathrm{C}$ in summer and $2-4{ }^{\circ} \mathrm{C}$ in autumn. The base and the future precipitation and temperature data were prepared to validate ANN model for the simulation of monthly runoff in the base and future periods. The results show that in the future, the discharge of Gharehsoo River watershed decreases in the all of months. In addition, the peak discharge in the future period happens 1 month earlier, because of increase of temperature and earlier beginning of snow melting season. Finally, the sensitivity of precipitation and temperature to runoff was investigated. The results showed that 1 and $2{ }^{\circ} \mathrm{C}$ increase of temperature lead to $0.05-8.2 \%$ and $0.1-13.4 \%$ decrease of average monthly discharge, respectively. In addition, monthly discharge increases $2.3-35.2 \%$ and decreases $1.4-29.4 \%$ due to $20 \%$ increase and decrease of precipitation, respectively.

\section{References}

Akhtar M, Ahmad N, Booij MJ (2008) he impact of climate change on the water resources of Hindukush-Karakorum-Himalaya region under different glacier coverage scenarios. J Hydrol 355:148-163

Arnell NW (1998) Climate change and water resources in Britain. Clim Change 39:83-110

Arnell NW (1999) Climate change and global water resources. J Global Environ Change 9:31-49

Ashouri H, Abrishamchi A, Moradkhani H, Tajrishy M (2008) Assessment of interannual and interdecadal climate variability effects on water supply in Zayandehrood River Basin, Iran. In: The First International Conference on Water Resources and Climate Change, Sultanate of Oman

Bougadis J, Adamowski K, Diduch R (2005) Short-term municipal water demand forecasting. Hydrol Process 19:137-148

Bray M, Han D (2004) Identification of support vector machines for runoff modelling. J Hydroinf 6(4):265-280

Chang H, Jung W (2010) Spatial and temporal changes in runoff caused by climate change in a complex large river basin in Oregon. J Hydrol 388:186-207

Chiew F, McMahon T (1994) Application of the daily rainfall runoff model MODHYDROLOG to 28 catchments. J Hydrol 153(1-4):383-416

Dawson CW, Wilby RL (2001) Hydrological modeling using artificial neural networks. Prog Phys Geogr 25(1):80-108

De Martonne E (1926) Aérisme et indice d'aridité. Comptes rendus de l'Académie des Sciences 182:1395-1398

De Vos NJ, Rientjes THM (2005) Constraints of artificial neural networks for rainfall-runoff modeling: trade-offs in hydrological state representation and model evaluation. Hydrol Earth Syst Sci 9:111-126

Fowler HJ, Kilsby CG (2007) Using regional climate model data to simulate historical and future river flows in northwest England. Clim Change 80:337-367

Gellens D, Roulin E (1998) Streamflow response of Belgian catchments to IPCC climate change scenarios. J Hydrol 210:242-258

Gordon CC, Cooper C, Senior CA, Banks H, Gregory JM, Mitchell JFB, Wood RA (2000) The simulation of SST, sea ice extents and ocean heat transport in a version of the Hadley centre coupled model without flux adjustment. Clim Dyn 16:147-168

Gutowski WJ, Decker SG, Donavon RA, Pan Z, Arritt RW, Takle ES (2003) Temporal-spatial scales of observed and simulated precipitation in central US climate. J Clim 16:3841-3847 
Hagan MT, Menhaj M (1994) Training feedforward networks with the Marquardt algorithm. IEEE Trans Neural Netw 5(6):989-993

Hagan MT, Demuth HB et al (1996) Neural network design. PWS Publishing, Boston

Han D, Chan L, Zhu N (2007a) Flood forecasting using support vector machines. J Hydroinf 9(4):267-276

Han D, Kwong T, Li S (2007b) Uncertainties in real-time flood forecasting with neural networks. Hydrol Process 21:223-228

Hay LE, Clark MP, Wilby RL, Gutowski WJ, Leavesley GH, Pan Z, Arritt RW, Takle ES (2002) Use of regional climate model output for hydrological simulations. J Hydrometeorol 3:571-590

Huntington TG (2003) Climate warming could reduce runoff significantly in New England, USA. Agric For Meteorol 117:193-201

Jakeman JJ, Littlewood IG, Whitehead PG (1990) Computation of the instantaneous unit hydrograph and identifiable component flows with application to two small upland catchments. J Hydrol 117:275-300

Javan K, Nasiri Saleh F, Shahraiyni HT (2013) The influences of climate change on the runoff of Gharehsoo River Watershed. Am J Clim Change 2:296-305

Johnston K, VerHoef JM, Krivoruchko K, Lucas N (2001) Using ArcGIS geostatistical analyst. ESRI Press, Redlands

Jones RG, Noguer M, Hassell DC, Hudson D, Wilson SS, Jenkins GJ, Mitchell JFB (2004) Generating high resolution climate change scenarios using PRECIS. Met Office Hadley Centre, Exeter, p 40

Kay AL, Jones RG, Reynard NS (2006a) RCM rainfall for UK flood frequency estimation. I. Method and validation. J Hydrol 318:151-162

Kay AL, Jones RG, Reynard NS (2006b) RCM rainfall for UK flood frequency estimation. II. Climate change results. J Hydrol 318:163-172

Kokkonen TS, Jakeman AJ (2001) A comparison of metric and conceptual approaches in rainfall-runoff modeling and its implications. Water Resour Res 37(9):2345-2353

Middelkoop H, Daamen K, Gellens D, Grabs W, Kwadijk JCJ, Lang H, Parmet BWAH, Schädler B, Schulla J, Wilke K (2001) Impact of climate change on hydrological regimes and water resources management in the Rhine Basin. Clim Change 49:105-128

Nash L, Gleick P (1991) The sensitivity of streamflow in the Colorado basin to climatic changes. J Hydrol 125:221-241

Nayak PC, Sudheer KP, Rangan DM, Ramasastri KS (2005) Shortterm flood forecasting with a neurofuzzy model. Water Resour Res 41:1-16

Nayak PC, Sudheer KP, Jain SK (2007) Rainfall-runoff modeling through hybrid intelligent system. Water Resour Res 43:1-17

Neira Mendez FH (2005) Assessment of climate indices in drylands of Colombia. Msc thesis in the Universitei t Gent, Belgium

Ranjan SP, Kazama S, Sawamoto M (2006) Effects of climate and land use changes on groundwater resources in coastal aquifers. J Environ Management 80:25-35

Shamseldin AY (1997) Application of a neural network technique to rainfall-runoff modeling. J Hydrol 199(3-4):272-294

Sujana D, Asis M (2009) Hydrological modelling of the Kangsabatiriver under changed climate scenario: case study in India. J of Hydrol Process 23:2394-2406

VanderKwaak JE, Loague K (2001) Hydrologic-response simulations for the R-5 catchment with a comprehensive physics-based model. Water Resour Res 37(4):999

Vicuna S, Garreaud RD, McPhee J (2011) Climate change impacts on the hydrology of a snowmelt driven basin in semiarid Chile. J Clim Change 105:469-488

Watson RT, Zinyowera MC, Moss RH (1996) Climate Change 1995: impacts, adaptations, and mitigations of climate change. Cambridge University Press, Cambridge p $\mathbf{8 8 9}$

Wilby RL, Hay LE, Leavesley GH (1999) A comparison of downscaled and raw GCM output: implications for climate change scenarios in the San Juan River basin. Colorado J Hydrol 225:67-91

Yu PS, Yang TC, Wu CK (2002) Impact of climate change on water resources in southern Taiwan. J Hydrol 260(1-4):161-175

Zarghami M, Abdi A, Babaeian I, Hassanzadeh Y, Kanani R et al (2011) Impacts of climate change on runoffs in East Azerbaijan, Iran. Glob Planet Change. doi:10.1016/j.gloplacha.2011.06.003 